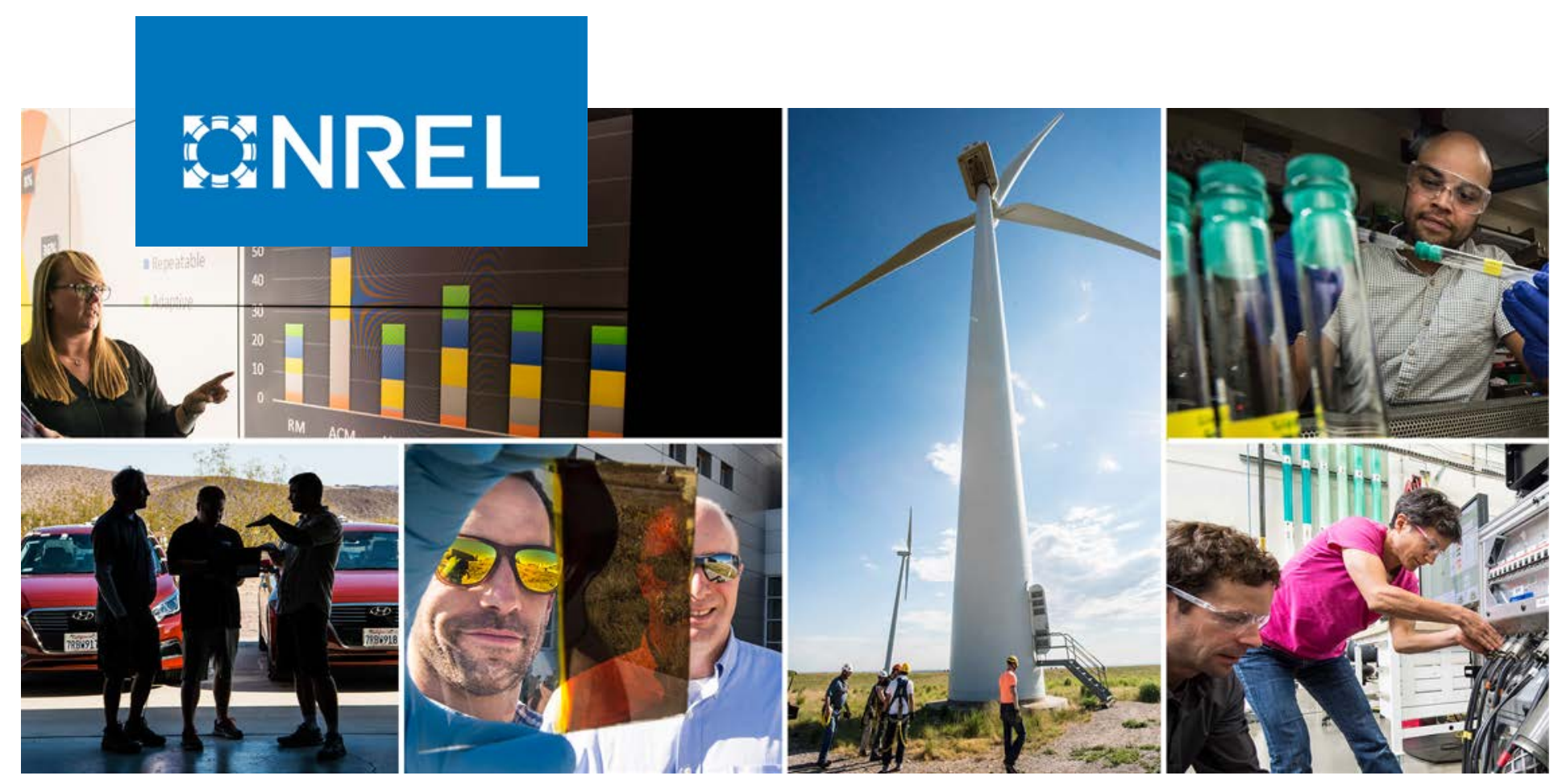

\title{
The Value of Increased HVDC Capacity Between Eastern and Western U.S. Grids: The Interconnections Seam Study
}

\section{Preprint}

Aaron Bloom, ${ }^{1}$ Josh Novacheck, ${ }^{2}$ Greg Brinkman, ${ }^{2}$ James McCalley, ${ }^{3}$ Armando L. Figueroa-Acevedo, ${ }^{4}$ Ali Jahanbani-Ardakani, ${ }^{3}$ Hussam Nosair,${ }^{5}$ Abhinav Venkatraman, ${ }^{3}$ Jay Caspary, ${ }^{6}$ Dale Osborn, ${ }^{7}$ and Jessica Lau ${ }^{2}$

1 NextEra Analytics

2 National Renewable Energy Laboratory

3 lowa State University

4 Black and Veatch

5 NYISO

6 Grid Strategies, LLC

7 Retired, formerly with the Midcontinent Independent System Operator

Submitted to IEEE Transactions on Power Systems

This work has been submitted to the IEEE for possible publication. Copyright may be transferred without notice, after which this version may no longer be accessible.

NREL is a national laboratory of the U.S. Department of Energy

Office of Energy Efficiency \& Renewable Energy

Operated by the Alliance for Sustainable Energy, LLC

This report is available at no cost from the National Renewable Energy Laboratory (NREL) at www.nrel.gov/publications.
Journal Article

NREL/JA-6A20-76850

October 2020 


\section{GNREL}

\section{The Value of Increased HVDC Capacity Between Eastern and Western U.S. Grids: The Interconnections Seam Study}

\section{Preprint}

Aaron Bloom, ${ }^{1}$ Josh Novacheck, ${ }^{2}$ Greg Brinkman, ${ }^{2}$ James McCalley, ${ }^{3}$ Armando L. Figueroa-Acevedo, ${ }^{4}$ Ali Jahanbani-Ardakani, ${ }^{3}$ Hussam Nosair ${ }^{5}$ Abhinav Venkatraman, ${ }^{3}$ Jay Caspary, ${ }^{6}$ Dale Osborn, ${ }^{7}$ and Jessica Lau ${ }^{2}$

1 NextEra Analytics

2 National Renewable Energy Laboratory

3 lowa State University

4 Black and Veatch

5 NYISO

6 Grid Strategies, LLC

7 Retired, formerly with the Midcontinent Independent System Operator

NREL is a national laboratory of the U.S. Department of Energy Office of Energy Efficiency \& Renewable Energy Operated by the Alliance for Sustainable Energy, LLC

This report is available at no cost from the National Renewable Energy Laboratory (NREL) at www.nrel.gov/publications.

Contract No. DE-AC36-08GO28308
Journal Article

NREL/JA-6A20-76850

October 2020

National Renewable Energy Laboratory 15013 Denver West Parkway Golden, CO 80401

303-275-3000 • www.nrel.gov 


\section{NOTICE}

This work was authored in part by the National Renewable Energy Laboratory, operated by Alliance for Sustainable Energy, LLC, for the U.S. Department of Energy (DOE) under Contract No. DE-AC36-08GO28308. Funding provided by the U.S. Department of Energy Office of Energy Efficiency and Renewable Energy Wind Energy Technologies Office and the U.S. Department of Energy Office of Electricity, in support of the Grid Modernization Initiative. The views expressed herein do not necessarily represent the views of the DOE or the U.S. Government. The U.S. Government retains and the publisher, by accepting the article for publication, acknowledges that the U.S. Government retains a nonexclusive, paid-up, irrevocable, worldwide license to publish or reproduce the published form of this work, or allow others to do so, for U.S. Government purposes.

This report is available at no cost from the National Renewable Energy Laboratory (NREL) at www.nrel.gov/publications.

U.S. Department of Energy (DOE) reports produced after 1991 and a growing number of pre-1991 documents are available free via www.OSTI.gov.

Cover Photos by Dennis Schroeder: (clockwise, left to right) NREL 51934, NREL 45897, NREL 42160, NREL 45891, NREL 48097, NREL 46526.

NREL prints on paper that contains recycled content. 


\title{
The Value of Increased HVDC Capacity Between Eastern and Western U.S. Grids: The Interconnections Seam Study
}

\author{
A. Bloom, Member, IEEE, J. Novacheck, Member, IEEE, G. Brinkman, Member, IEEE, J. McCalley, Fellow, IEEE, \\ A. L. Figueroa-Acevedo, Member, IEEE, A. Jahanbani-Ardakani, H. Nosair, A. Venkatraman, J. Caspary, Member, IEEE, \\ D. Osborn, Senior Life Member, IEEE, and J. Lau, Member, IEEE
}

\begin{abstract}
The Interconnections Seam Study examines the potential economic value of increasing electricity transfer between the Eastern and Western Interconnections using high-voltage directcurrent (HVDC) transmission and cost-optimizing both generation and transmission resources across the United States. The study conducted a multi-model analysis that used co-optimized generation and transmission expansion planning and production cost modeling. Four transmission designs under eight scenarios were developed and studied to estimate costs and potential benefits. The results show benefit-to-cost ratios that reach as high as 2.9 , indicating significant value to increasing the transmission capacity between the interconnections under the cases considered, realized through sharing generation resources and flexibility across regions.

Index Terms - HVDC transmission, Interregional transmission, Power generation dispatch, Power system economics, Power system reliability, Power system planning, Resource adequacy, Solar power generation, Wind power generation.
\end{abstract}

\section{INTRODUCTION}

A $t$ the western edge of the American prairie, just east of the Rocky Mountains, lies a collection of electrical transmission resources that tie together the otherwise segregated U.S. and Canadian Eastern and Western Interconnections (EI and WI). These seven back-to-back (B2B) high-voltage direct-current (HVDC) facilities enable 1,320 megawatts (MW) of electricity to flow between the U.S. EI and WI. ${ }^{1}$ This transfer capability between the interconnections is very small compared to the networks they connect - the larger EI is home to $700,000 \mathrm{MW}$ of generating capacity, and the WI roughly $250,000 \mathrm{MW}$. But as small as these B2B facilities may be, they are important: they are located strategically at the "seam" where the East meets the West-and with the U.S. resource portfolio in transition, the ability to share additional resources across the seam could be economically attractive under a variety of possible futures. At the same time, these facilities are aging, and thus their continued use will require additional investment for keeping them in service. These observations suggest that increasing cross-seam transmission capacity may represent a timely and impactful opportunity for utilities, developers, regulators, and policy makers to modernize and strengthen the U.S. electric grid.

Over the last 95 years, a number of entities have indicated interest in developing additional cross-seam transmission. The earliest [1], in 1923, was motivated by a desire to integrate the continent's hydro and coal resources. Subsequent studies $[2,3,4$, 5] investigated joining the existing systems for economic and/or reliability benefits. An HVDC overlay of the U.S. western and
Midwestern grids was proposed in [6]. Reference [7] argued for an integrated alternating-current/direct-current (AC/DC) approach and illustrated a national overlay design of predominantly $765 \mathrm{kV}$ $\mathrm{AC}$ lines. More recent work $[8,9,10]$ applied generation and transmission co-optimization on a set of geographically aggregated electric nodes across the United States to design a national transmission network that was shown to be economically attractive under various futures. A variety of challenges have prevented nationwide HVDC overlays from development so far. References $[11,12]$ describe transmission planning efforts around the world, including HVDC overlay designs.

Here we present the Interconnections Seam Study, a coordinated transmission planning analysis of the two major U.S. interconnections. The study co-optimizes capacity expansion and systems operations to quantify the potential value of increasing the transmission capacity between the EI and WI using HVDC technology to facilitate more economically efficient exchange of power and adequacy throughout the United States. The work described in this paper differs from previous efforts in three ways: (1) Study objective: The objective was to identify the value of increased cross-seam transmission capacity; as a result, several HVDC designs were studied —one of which, called the macrogrid, has features similar to those of previously developed overlays.

(2) Analysis fidelity: The study uniquely captures capacity expansion and production cost at an unprecedented geographic scale and detail, all performed with consistent data inputs. The production cost modeling deploys a novel geographic decomposition computational method to more precisely represent operational constraints, enable increased modeling resolution, and reduce solve time.

(3) HVDC and AC transmission: In each cross-seam transmission design, HVDC capacity was co-optimized not only with generation investments but also with $\mathrm{AC}$ transmission investments; this process ensured that $\mathrm{AC}$ transmission investment needs were satisfied.

\section{APPROACH}

To ensure the technical rigor of this study, a technical review committee (TRC) including more than 20 organizations met on six occasions to discuss the approach, methods, scenarios, data, assumptions, and results. The study provides initial valuations of increasing connection between the interconnections but should not be referenced as reporting final ready-to-build designs. It also does not take the place of regional planning studies, but can provide

${ }^{1}$ An additional $150 \mathrm{MW}$ of $\mathrm{B} 2 \mathrm{~B}$ transmission capacity is in Alberta, Canada; it was modeled, but not considered for expansion. 
analysis of potential ways regions can benefit from inter-regional planning efforts. Similarly, the study does not obviate the need for state and federal siting review. The study did not consider the impact on wholesale rates set by the Federal Energy Regulatory Commission or North American Electric Reliability Corporation (NERC) reliability standards under Federal Power Act Sections 203, 205, and 206.

The first step of the study was to conduct a detailed capacity expansion analysis for four future (through 2038) transmission designs and eight different generation scenarios developed using differing assumptions regarding transmission costs, renewable generation, wind and solar costs, gas prices, and retirements (see Table 1). Each of the 32 simulated power systems (four transmission designs applied to eight scenarios) meet long-term simplified, single-year, consistent, resource adequacy requirements. In the base case, the systems are expanded costoptimally based on state renewable portfolio standards existing in 2017 and business-as-usual assumptions for generation technology cost improvement. We then created detailed nodal transmission models to evaluate the ability of the power system to reliably schedule and dispatch generation to meet demand at all hours of the year for select scenarios.

TABLE 1

Description of the Scenarios*

\begin{tabular}{|c|c|}
\hline Scenario & Key assumption differences \\
\hline Base Case & AEO 2017 gas price, state RPS laws \\
\hline $\begin{array}{l}\text { Low Gas } \\
\text { Price }\end{array}$ & $\begin{array}{l}\text { AEO } 2017 \text { High Gas Resource (regionally } \\
\text { and temporally varying around } \$ 4 / \mathrm{mmbtu} \text { ) }\end{array}$ \\
\hline $\begin{array}{l}\text { High Gas } \\
\text { Price }\end{array}$ & $\begin{array}{l}\text { AEO } 2017 \text { Low Gas Resources gas prices } \\
\text { (varying around } \$ 6 / \mathrm{mmbtu} \text { ) }\end{array}$ \\
\hline $\begin{array}{l}\text { High AC Trx } \\
\text { Cost }(1.5 x)\end{array}$ & $\begin{array}{l}50 \% \text { higher than base transmission cost. } \\
\text { Base transmission cost from [16] }\end{array}$ \\
\hline $\begin{array}{l}\text { High AC Trx } \\
\text { Cost }(2 x)\end{array}$ & Double the base transmission cost \\
\hline $\begin{array}{l}\text { No } \\
\text { retirements }\end{array}$ & $\begin{array}{l}\text { Model does not retire any generating units } \\
\text { beyond announced retirements }\end{array}$ \\
\hline $\begin{array}{l}\text { Low-cost } \\
\text { renewables }\end{array}$ & ATB 2017 Low-Cost VG \\
\hline High VG & $\begin{array}{l}\text { Least-cost generation mix when using a } \\
\text { carbon cost from } \$ 3 / \text { tonne in } 2024 \text { to } \\
\$ 45 / \text { tonne in } 2038^{* *}\end{array}$ \\
\hline
\end{tabular}

*Acronyms used here include Energy Information Administration (EIA) Annual Energy Outlook (AEO); Renewable Portfolio Standard (RPS); Annual Technology Baseline (ATB) (atb.nrel.gov); Variable Generation (VG)

**: The study TRC recommended this approach (consistent with cost estimates in [17]) as a proxy for potential growth in wind and solar in light of uncertainty in traditional deployment forecasts [18].

Table 2 summarizes the four interregional transmission designs considered in the generation scenarios. In all designs, new AC transmission and generation are co-optimized to minimize systemwide costs in addition to the HVDC and B2B facility expansions allowed under each transmission design. For co-optimized generation and transmission expansion, we used Iowa State University's co-optimized generation and transmission plan
(CGT-Plan) model [14]. Energy Exemplar's PLEXOS was used for production cost modeling (PCM).

TABLE 2

Summary of Transmission Designs

\begin{tabular}{|l|l|}
\hline Design Name & Description \\
\hline Design 1 (D1) & $\begin{array}{l}\text { Existing B2B facilities are maintained at } \\
\text { their 2017 capacity }\end{array}$ \\
\hline Design 2a (D2a) & $\begin{array}{l}\text { Existing B2B facilities are allowed to } \\
\text { expand in the optimization }\end{array}$ \\
\hline Design 2b (D2b) & $\begin{array}{l}\text { Three HVDC transmission segments } \\
\text { (along with the expansion of the B2Bs) } \\
\text { are built between the EI and WI }\end{array}$ \\
\hline Design 3 (D3) & $\begin{array}{l}\text { A national-scale HVDC transmission } \\
\text { network, or macrogrid, is built }\end{array}$ \\
\hline
\end{tabular}

\section{INPUT DATA AND ASSUMPTIONS}

A variety of input data and assumptions were used to build power system representation of the EI and WI. The near-term expected generation and transmission for the EI and WI was obtained from NERC regional entities. The Eastern Interconnection Reliability Assessment Group's (ERAG) Multiregional Modeling Working Group (MMWG) 2026 summer case and the Western Electricity Coordinating Council (WECC) Transmission Expansion Planning Policy Committee (TEPPC) 2024 common case were chosen as the starting point for creating an updated nodal representation of the 2024 EI and WI. Additional information on the 2024 data can be found in [13]. Both capacity expansion and production cost modeling used consistent data for the transmission topology, existing and expanded generation fleet, thermal plant operating characteristics, load forecasts, and timeseries data for wind and solar resources.

\section{A. Capacity Expansion Modeling}

The capacity expansion model, CGT-Plan, determines the location, size, and technology type for generation and transmission built in each scenario. It does this by minimizing generation and transmission investment costs, generation retirement costs and generation production cost over time from 2024-2038 using 169 buses reduced from the 98,000 nodal 2024 U.S. EI and WI transmission networks. Production costs include, for new and existing resources, fixed and variable operating and maintenance costs, fuel cost and operational reserve cost (regulation up/down and contingency reserve). Constraints imposed include: power balance at each node; "DC" angle constraints across each existing line; upper and lower limits on generation dispatch and line flows; lower limits on available up/down regulation reserves and available contingency reserves; upper limits on up/down regulation (contingency) reserves by the unit's 1-minute (10-minute) ramp rate; capacity in excess of the NERC-recommended $115 \%$ of peak [14] (all units contributed to the planning reserve according to each units capacity value which, for wind and solar, varied locationally as described in [15] but were independent of renewable penetration); and the definition of the particular transmission design being studied. Operational reserves were imposed systemwide; a capacity constraint was imposed in each of four regions: 
West, Northwest, Midwest, and East. A full description of the model is available at [15].

CGT-Plan was run 32 times, for each of the four designs, D1, D2a, D2b, and D3 under the eight scenarios. CGT-Plan identified investments in two-year increments to minimize net present value of investments plus operational costs occurring during the 15-year decision horizon, plus operating costs occurring for another 20 years thereafter. Operations were simulated for every year using 19 conditions; wind and solar were dispatched using a $P_{\max }$ set by their capacity factor (for energy blocks) or capacity value (for peak blocks) and were redispatched down under congested conditions as necessary; flexibility requirements were modeled as a function of net-load variability. The 19 conditions included 15 "energy blocks" capturing five time periods in each of three seasons (summer, winter, and shoulder): 1-7 a.m., 8 a.m. -12 p.m., 1-4 p.m., 5-6 p.m., and 7 p.m.-12 a.m. The remaining four conditions were "peak net-load blocks" to capture one-hour annual peak conditions in each of four regions. The peak blocks were used to model the capacity constraint; because different regions peak at different times of the year, this enabled analysis of interregional reserve-sharing subject to transmissionrelated deliverability constraints [15].

Decision variables included investment in various generation and transmission technologies, as well as retirement of existing generation. Percentage of load served by $\mathrm{VG}$ ranged from approximately $30 \%$ to $40 \%$ in the base case and high VG case, respectively. All generation assets were based on commercially available technologies in 2017 and were modeled with appropriate maturation rates at all buses. The natural gas price assumption for the Base Case was adopted from the U.S. Energy Information Agency's (EIA) 2017 AEO [19]; the nominal price for electric generation ranged by region from $\$ 4.2 /$ million British thermal units (MBTU) to $\$ 5.1 / \mathrm{MBTU}$ in 2024; these assumed prices are similar to those projected in the "low oil and gas supply curve" of the 2020 EIA AEO [20]. Battery energy storage was not an investment option. At each bus, the wind resources available for selection included three 100-meter wind technologies, each having different costs and the ability to be optimized for unique wind resource characteristics by geography. This included three different capacity factor categories that identified the investment potential at a particular range of capacity factor. Investments in solar photovoltaics (PV) were limited to utility scale and were split evenly between single-axis tracking and fixed-tilt. Distributed PV capacity projections for 2024 came from the 2016 NREL Standard Scenarios [21], and a $3 \%$ per year growth rate [19] was applied until 2038.

Investment options among transmission technologies included additional AC capacity on any existing branch at the voltage of that branch, at a cost per mile appropriate for that voltage and the geography of the region. Table 1 summarizes the additional HVDC investments that are allowed in D2a, D2b, and D3. In D2a and D2b, B2B facilities could expand independently of one another. In D2b, the three additional HVDC lines connecting the EI and WI are required to develop equal capacity. Similarly, in D3, all segments of the macrogrid are required to maintain equal capacity. Although the N-1 reliability criterion was not explicitly imposed, the "equal capacity" constraints for the HVDC lines in D2b and D3 were employed as proxies to avoid significant violation of this criterion. For example, three equal-capacity parallel HVDC bipole lines can be loaded to capacity and withstand a monopole loss of any one of them (considered to be an $\mathrm{N}-1$ outage) if the remaining five poles can each provide an additional $20 \%$ capacity for a short time on their emergency overload ratings. Based on analysis of discount rates recommended by the White House Office of Management and Budget and other studies [21 - 23], we chose a nominal discount rate of $7.7 \%$ and an inflation rate of $2 \%$, resulting in a real discount rate of $5.7 \%$. Demand growth was set within each region consistent with recent studies [24, 25]; technology costs and regional multipliers for all generation resources and $\mathrm{AC}$ and HVDC transmission were based on [16, 26-29]. A capacity credit is given to each generator type and is the percent of that unit's capacity that can be applied towards satisfying the annual peak $[30,31]$. Other data and associated sources are identified in [15, 32]. After the translation (III.B) and PCM (III.C) were completed on the penultimate CGT-Plan runs, the CGT-Plan was re-run for analysis presented in the results section on costs and benefits (IV.C), this time allowing a comprehensive set of transmission interfaces to be expanded and considering load growth end effects beyond 2038 in the optimization.

\section{B. Translation from Capacity Expansion to Production Cost Modeling}

CGT-Plan developed year-2038 aggregated zonal transmission and generation for the EI and WI. In order to study the year-2038 operation of these systems and determine operational savings (in perpetuity) due to the HVDC and B2B facilities, a nodal production cost model (PCM) of the 2038 system was created. This required a translation of the CGT-Plan zonal generation and transmission results to the nodal PCM network. This is a two-step process that begins with a 2024 nodal transmission model. Step 1 distributes generation investments and retirements identified by CGT-Plan according to the 2024 nodal model, using the following criteria: (i) Individual generating units are retired in the 2024 model based on heat rate until the CGT-Plan retirement amounts are satisfied; (ii) CGTPlan new thermal generators are added at locations in the 2024 model where thermal plants were retired; and (iii) wind and PV investments identified by CGT-Plan were added to the highvoltage node $(\geq 230 \mathrm{kV})$ in the PCM that is geographically closest to the wind and PV sites.

Step 1 resulted in a nodal model that contained 2038 load and generation for the PCM (from CGT-Plan) but did not update the transmission system. For step 2, we developed a transmission expansion planning (TEP) optimization program and applied it to the nodal PCM obtained from Step 1. This optimization is nonlinear, given each transmission investment changes the circuit capacity and the circuit reactance. To address this, we developed the TEP as a sequence of linear programs (LPs), where each LP minimized the total transmission investment cost (subject to DC power flow equations), and only circuit capacity was treated as a decision variable, while circuit reactance was held constant. Following the LP solution, the reactance of each invested circuit was updated to reflect the change in capacity, after which the LP was rerun. The iterations were terminated when the circuit with the largest change in capacity relative to the previous iteration was within a specified tolerance. This two-step process results in 
a nodal version of the 2038 systems created by CGT-Plan, which is used in the PCM.

\section{Production Cost Modeling}

The nodal PCM that resulted from the capacity expansion scenarios was used to simulate a full year of continuous operation in the year 2038. The simulation has two phases, a day-ahead unit commitment, made up of 365 serial optimizations, and a real-time dispatch in which 8,760 serial optimizations are completed. Each day-ahead unit commitment optimization is a mixed integer linear program that considers 24 hourly decisions with additional 24 hours of look-ahead information. The look-ahead is used to improve decisions about the operations of energy-limited resources and units with long minimum online/offline times. The real-time dispatch is also a mixed integer linear program that only considers a single hourly decision at a time.

Barrows et al. [33] summarizes the system of equations that define the optimization problem for each phase of the PCM. The objective function minimizes the total cost to operate the system, while deciding which generating units to start or shut down and how much power online units should generate. Constraints to the objective functions include requiring total system generation meet total system load, the technical limitations of generators (such as ramp rates and minimum up/down times), temporal energy limits, nodal power balance, and linearized power flow equations, among others.

We adopted a new decomposition method described in [34] to complete the day-ahead unit commitment phase to improve representation of realistic operations for multiple regions and reduce solve times by three orders of magnitude. This method enables the unit commitment and dispatch to be simulated independently for each region (independent system operator (ISO)/regional transmission organization (RTO) equivalent).

The 2038 PCM includes approximately 13,000 generating units, 98,000 transmission nodes, and 96,000 transmission lines and transformers. Wind data is from the Wind Integration National Dataset (WIND) Toolkit, and solar data is from the National Solar Radiation Database (NSRDB). ${ }^{2}$ Load data is from multiple sources, including the various RTOs, ISOs, and Federal Energy Regulatory Commission (FERC) [13]. Weather conditions for the years 2007-2013 were evaluated for use in the PCM. A geospatial analysis of wind and solar resource availability identified 2012 as the closest to average across the seven-year data set, so the 2012 data was used for wind, solar, and load to maintain correlations and time synchronicity between these data sets.

Thermal plant assumptions were adopted from [35] and enabled detailed modeling of every thermal generator. When possible, existing thermal plants that are still in operation in 2038 have unitspecific plant flexibility characteristics that were extracted by analyzing the Environmental Protection Agency's Continuous Emissions Monitoring System. When unit-specific data was unavailable, generic assumptions were made based on the generator vintage and type.

Contingency and regulation reserves are held regionally, either by ISO/RTO boundary or by FERC Order 1000 planning region.
The amount of regulation required is calculated using the method described in Ibanez et al. [36]. The method determines the amount of reserves required to cover the uncertainty and variability of the load, wind, and solar.

\section{RESUltS}

\section{A. Costs and Benefits}

In this section, we describe the results of the generation and transmission expansion through 2038, for the four transmissions designs in the base case (Table 3) and then the suite of eight scenarios (Tables 4 and 5). The capacity expansion model was used to assess the costs and benefits of each of the study scenarios and designs, using the investment costs and operating costs for the years 2024-2038, plus 20 years with no load or generation growth after 2038 in order to reduce the impacts of end effects. Because D1 was the only design that did not allow cross-seam transmission investment, it is reference for comparison for the other three designs; positive numbers indicate cost increases and negative indicates cost decreases. The investment and operational costs for each transmission design in the base case are presented in Table 3, where we observe that the 35-year net cost change (total transmission and generation investment costs plus operational cost, relative to D1) is greatest for D2b and D3 in each scenario.

An important observation from Table 3 is that the benefit-to-cost $(\mathrm{B} / \mathrm{C})$ ratio, calculated as the change (relative to D1) in the generation investment and operational cost divided by the change in the transmission investment cost, is well above the industry threshold of 1.25 considered necessary to justify transmission investments [37]. Most of the benefit occurs as a result of reduction in generation operational costs enabled by increased transfer capability provided by transmission builds. The values shown may be considered as lower bounds on $\mathrm{B} / \mathrm{C}$ ratios since they do not reflect externalities nor non-quantified benefits such as increased resiliency of the electric system to continue supplying low-cost energy during catastrophes such as large hurricanes and widespread wildfires. While including these details could increase overall costs of the scenarios, transmission would likely continue to have additional benefits.

TABLE 3

Summary of CGT-Plan Benefit/Cost Results for Base Scenario

\begin{tabular}{|l|r|r|r|r|}
\hline \multicolumn{1}{|c|}{$\begin{array}{c}\text { Capacity or Cost } \\
\text { Item }\end{array}$} & D1 & $\boldsymbol{\Delta D 2 a}$ & $\mathbf{\Delta D 2 b}$ & $\mathbf{\Delta D 3}$ \\
\hline $\begin{array}{l}\text { Transmission } \\
\text { Investment Cost, \$B }\end{array}$ & 40.03 & 2.57 & 6.76 & 8.19 \\
\hline $\begin{array}{l}\text { Generation Investment } \\
\text { Cost, \$B }\end{array}$ & 555.23 & 3.6 & 10.44 & 4.17 \\
\hline Operational cost, \$B & 2376.50 & -8.79 & -21.70 & -15.30 \\
\hline $\begin{array}{l}\text { 35-yr Net Cost change, } \\
\text { \$B }\end{array}$ & - & -2.62 & -4.5 & -2.94 \\
\hline 35-yr B/C ratio & - & 2.02 & 1.66 & 1.36 \\
\hline
\end{tabular}

Note: D1 results are shown as absolute costs; D2a, D2b, and D3 results are shown relative to D1.

\footnotetext{
${ }^{2}$ https//www.nrel.gov/grid/wind-toolkit.html; http://nsrdb.nrel.gov/
} 
Tables 4 and 5 show the 35-year net cost savings and benefit to cost ratios for D2a, D2b and D3, relative to D1 for the various scenarios. The cost (net present value) of the $\mathrm{D} 1$ design under the base case conditions is \$B29,712. Though D2a consistently produces the highest $\mathrm{B} / \mathrm{C}$ ratio among the three cases per sensitivity, D2b results in the greatest potential net cost savings.

TABLE 4

35-year Net Cost Savings for Sensitivities (\$B)

\begin{tabular}{|l|l|l|l|}
\hline Sensitivity & $\mathbf{\Delta D 2 a}$ & $\mathbf{\Delta D 2 b}$ & $\mathbf{\Delta D 3}$ \\
\hline Base Case & -2.62 & -4.5 & -2.94 \\
\hline Low Gas Price & -2.91 & -4.15 & -2.38 \\
\hline High Gas Price & -4.67 & -9.51 & -5.88 \\
\hline High AC Trx Cost (1.5x) & -2.23 & -5.35 & -4.56 \\
\hline High AC Trx Cost (2x) & -2.08 & -5.46 & -5.48 \\
\hline No retirements & -1.24 & -1.58 & -0.82 \\
\hline Low-cost renewables & -2.87 & -4.78 & -3.00 \\
\hline High VG & -18.35 & -28.83 & -23.04 \\
\hline
\end{tabular}

Note: D2a, D2b, and D3 results are shown as savings relative to D1. Emission costs included in the High VG scenario are not included in Net Costs.

TABLE 5

35-year Benefit/Cost Ratio for Sensitivities

\begin{tabular}{|l|l|l|l|}
\hline Sensitivity & $\boldsymbol{\Delta D 2 a}$ & $\mathbf{\Delta D 2 b}$ & $\mathbf{\Delta D 3}$ \\
\hline Base Case & 2.02 & 1.66 & 1.36 \\
\hline Low Gas Price & 1.81 & 1.52 & 1.22 \\
\hline High Gas Price & 1.76 & 1.84 & 1.46 \\
\hline High AC Trx Cost (1.5x) & 1.87 & 1.45 & 1.29 \\
\hline High AC Trx Cost (2x) & 2.26 & 1.52 & 1.37 \\
\hline No retirements & 1.98 & 1.72 & 1.33 \\
\hline Low-cost renewables & 2.53 & 1.77 & 1.56 \\
\hline High VG & 2.09 & 2.89 & 1.80 \\
\hline
\end{tabular}

Note: D2a, D2b, and D3 results are shown relative to D1. Emission costs included in the High VG scenario are not included in ratio.

The $\mathrm{B} / \mathrm{C}$ ratio in almost every case (except $\mathrm{D} 3$ for the low gas price case) remains above the 1.25 threshold mentioned above. In most cases, it is significantly higher.

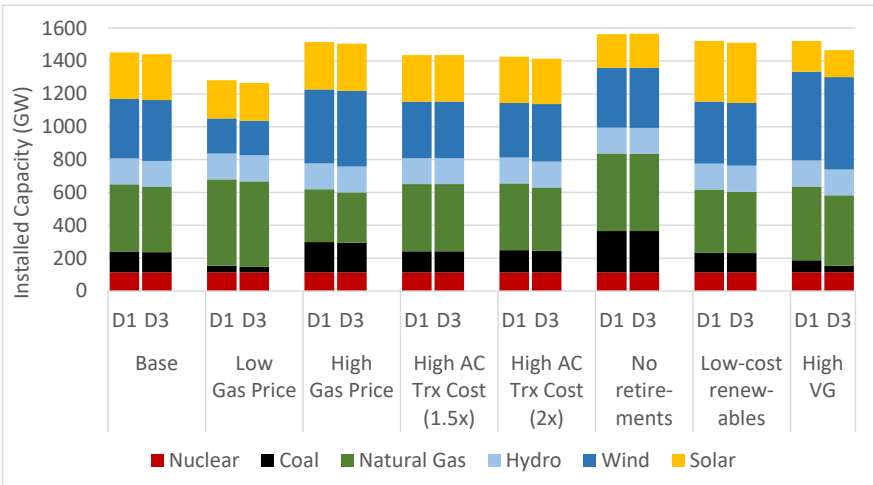

Fig. 1. Installed generation capacity by resource type in 2038 . The installed capacity was determined using CGT-Plan.

The 2038 installed generation capacity from CGT-Plan is presented in Fig. 1 for D1 and D3. Maps of the resulting AC and
DC (post-translation) transmission additions are shown in Fig. 2. Fig. 1 reveals a slight decrease in installed capacity in all scenarios in designs D3, relative to D1 (D2a and D2b, not shown, are all between D1 and D3). The High VG scenario has the largest capacity reduction and the most transmission. Tables 6 and 7 identify the additional transmission capacity added in the Base and High VG scenarios. Each design requires significant $\mathrm{AC}$ transmission expansion, but this AC transmission expansion is less for the designs with high HVDC capacity (D2b and D3). Additional details on the CGT-Plan modeling are provided in [15].

TABLE 6

Transmission Investment Summary, Base Scenario

\begin{tabular}{|l|l|l|l|l|}
\hline \multicolumn{1}{|c|}{ Design $\rightarrow$} & D1 & D2a & D2b & D3 \\
\hline HVDC-B2B (GW) & 0 & 6.7 & 6.3 & 0 \\
\hline HVDC-Line (GW-miles) & 0 & 0 & 14,487 & 29,062 \\
\hline AC Line (GW-miles) & 18,409 & 19,357 & 17,778 & 16,076 \\
\hline
\end{tabular}

Note: New transmission investments are identified, for B2B in terms of GW increased capacity between B2B terminals; and also, for lines, in terms of GWmiles, which is the GW capacity multiplied by the path distance.

TABLE 7

Transmission Investment Summary, High VG Scenario

\begin{tabular}{|l|l|l|l|l|}
\hline \multicolumn{1}{|c|}{ Design $\rightarrow$} & D1 & D2a & D2b & D3 \\
\hline HVDC-B2B (GW) & 0 & 25.7 & 7.5 & 0 \\
\hline HVDC-Line (GW-miles) & 0 & 0 & 31,335 & 63,156 \\
\hline AC Line (GW-miles) & 52,737 & 60,141 & 50,964 & 43,190 \\
\hline
\end{tabular}

\section{B. System Operations}

We use hourly PCM to help evaluate the operability of a given scenario by simulating an entire year of hourly operations, as opposed to the time slices used for capacity expansion. The PCM simulated the operations of the 2038 power systems built by the penultimate (and largely similar to the final) version of CGT-Plan buildout. We compare the base case to the high VG scenario, as they showed the most differences in $\mathrm{B} / \mathrm{C}$ ratio, net cost savings, and overall generation buildout. In those simulations, all of the power systems met all load in all hours and met $99.69 \%-99.97 \%$ of all contingency and regulation reserve requirements. In both of the capacity scenarios, D1, the design with the least cross-seam transmission capacity, had the largest total reserve shortage. In the PCM modeling, nuclear generation did not change across the scenarios. Fossil fuels provided $36 \%$ of generation in the four Base designs and approximately $26 \%$ in the four High VG designs. Wind and solar increased from just under $30 \%$ in the Base designs to just under $40 \%$ in the High VG designs.

VG curtailment ranged from $11 \%-15 \%$ across all scenarios and designs. A review of curtailment outcomes indicates that congestion on $\mathrm{AC}$ transmission lines is a significant driver of curtailment. Other options, such as additional energy storage investment or additional demand response, may also become economically attractive at these curtailment levels, but they were not considered as an investment option. Additional analysis is necessary to understand the tradeoffs between curtailment, transmission, storage, and other options.

In addition to assessing overall system performance in 2038, the PCM was also used to conduct a detailed analysis of extreme time periods based on 2012 load and meteorology. We present two such cases that reflect periods of high net-loads and ramping, as well as 
the value of cross-seam transmission in potentially mitigating them. The first period is the three-day period in August around the coincident peak load across the EI and WI. The hourly cross-seam flow across the B2B and HVDC lines during this period is displayed in Fig. 3. There is a strong diurnal pattern in the aggregate power flow across the interconnections seam during this period in all transmission designs. In the afternoon, the load in the EI begins to peak. At the same time, solar PV generation is high in the WI, while the WI load is still relatively low. Cross-seam lines are nearly fully loaded and are used to flow power from the WI to EI. As the sun begins to set on the West Coast, load decreases in the EI and wind in the Midwest increases its output. The flow on the cross-seam lines changes direction, delivering power from the EI to the WI. The lines export Midwestern wind power and power from thermal units that otherwise would have turned off after the EI peak load.
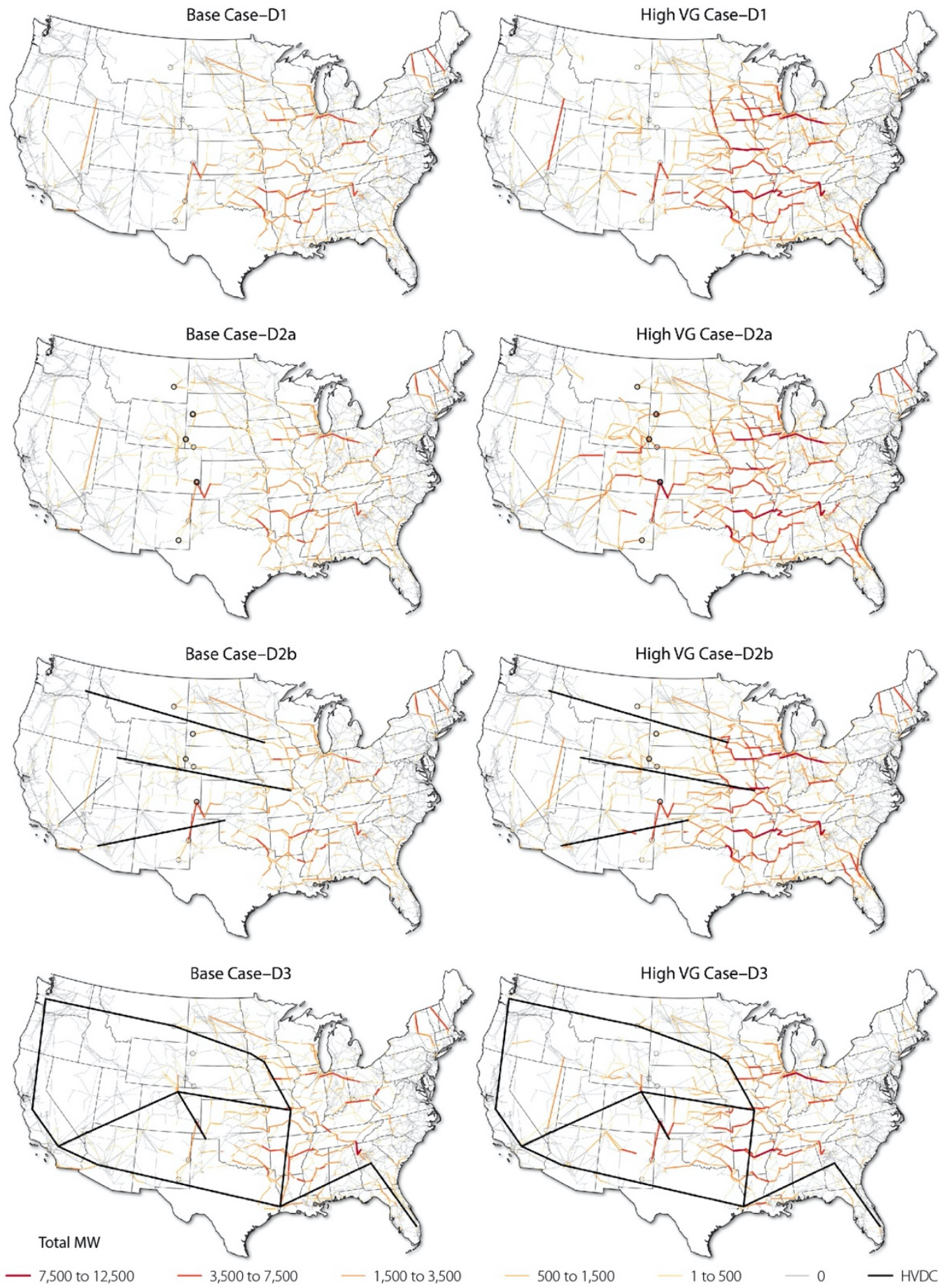

Fig. 2. Maps of the resulting AC and DC transmission additions between 2024 and 2038 from the TEP (i.e., post-translation and as modeled in the PCM). On the left are the four transmission designs in the base scenario. The results for the designs in the high VG scenario are on the right. 


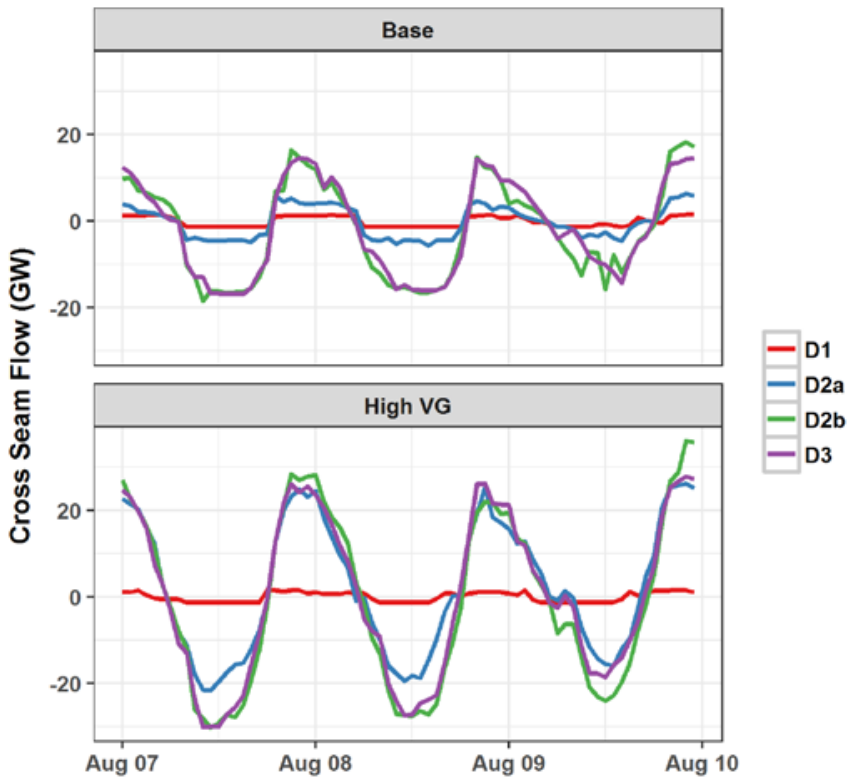

Fig. 3. Cross-seam transmission power flow (B2B and HVDC) during the coincident peak load period. A positive flow is a net export from the EI to the WI; a negative flow is a net import into the EI from the WI. Times are Eastern Standard Time.

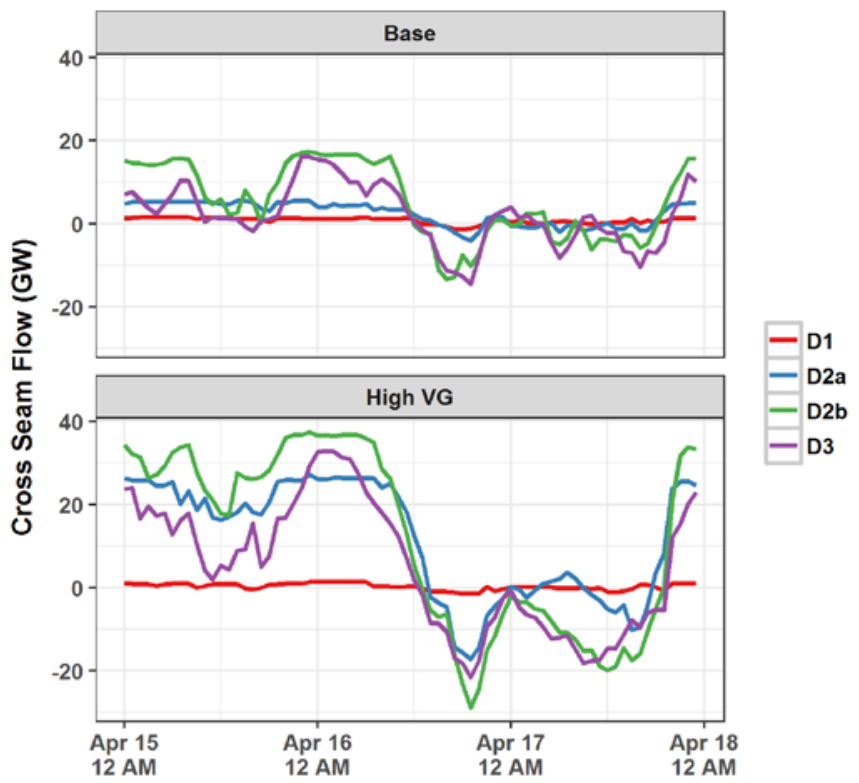

Fig. 4. Cross-seam transmission power flow (B2B and HVDC) during a large down-ramp in Midwest wind generation. A positive flow is a net export from the EI to the WI; a negative flow is a net import into the EI from the WI. Times are Eastern Standard Time.

We also analyzed a three-day period in April. On the first day of this period, April $15^{\text {th }}$, the VG instantaneous penetration hovers around $60 \%$ of total generation for all designs in both scenarios. VG curtailment is also significant throughout the day. However, in the late morning hours of the next day, April $16^{\text {th }}$, Southwest Power Pool (SPP) wind begins a steady ramp down, and a decrease in Midcontinent Independent System Operator (MISO) wind follows. Fig. 4 shows how cross-seam transmission helps respond to this event. On April $15^{\text {th }}$, the cross-seam HVDC is used to export wind from SPP and MISO to the WI. But as the wind power drops off on the morning of April $16^{\text {th }}$, the flow changes direction, and the
WI begins exporting to the EI. Rather than requiring SPP and MISO to deal with the down-ramp in wind on their own, crossseam transmission allows lower-cost resources in the WI to help balance the loss of the wind power on the other side of the seam.

\section{CONCLusions/NeXt StePS}

This study demonstrates significant novelty in its multi-model approach. Combining CGT-Plan and PCM allowed for a thorough assessment and evaluation of the benefits and costs of four alternative cross-seam transmission designs in the United States and eight generation and transmission cost scenarios. The study also deploys novel modeling techniques to 1) characterize the value of capacity sharing, and 2) enable a nodal simulation of every generator and transmission line in the two largest North American Interconnections.

The study shows with increased intercontinental transmission that the system was able to balance generation and load with less total system installed capacity across each of the generation scenarios, due to load and generation diversity, and increased operating flexibility. The results show benefit-to-cost ratios ranging from 1.2 to 2.9 , indicating significant value to increasing the transmission capacity between the interconnections and sharing generation resources for of all the cost futures studied. Production cost modeling identified that new lines would likely have high utilization during challenging operational periods throughout the year.

While fundamental elements of transmission and generation were represented throughout the study, additional modeling and analysis is required to further examine the alternative grid designs and evaluate the technical and economic benefits. Contingency analysis, particularly for new HVDC designs D2a, D2b, and D3, is an essential step in going forward. Industry review and input will remain vital to further evaluation of potential transmission expansion across the interconnections, as studies often present the most optimal solution given the model inputs. Additionally, this study does not address market adoption feasibility as well as other technical details needed to develop a more thorough understanding of system reliability implications (e.g. dynamic power flow, voltage stability, more complete contingency analysis). Full exploration of the potential benefits and costs of cross-seam transmission to the continent will require additional multi-model analysis.

This study provides a platform for conducting additional research at a large geographic scale. Potential reliability and resilience benefits of transmission could be explored through AC power flow studies with steady-state and stability modeling; consideration of system resilience and security requirements related to weather and extreme conditions; and incorporation of natural gas delivery infrastructure and gas-electric operational coordination. Additional analyses could estimate additional system- and local-level costs and benefits (e.g., economic and environmental impacts).

\section{ACKNOWLEDGMENT}

The authors gratefully acknowledge the contributions of Charlton Clark, Jian Fu, Kevin Lynn, and Kerry Cheung from the U.S. Department of Energy. Additional thanks go to Paul 
Denholm, Douglas Arent, and Mark O'Malley for their thoughtful review, and the TRC for their guidance.

This work was authored in part by the National Renewable Energy Laboratory, operated by Alliance for Sustainable Energy, LLC, for the U.S. Department of Energy (DOE) under Contract No. DE-AC36-08GO28308. Funding provided by the DOE Office of Energy Efficiency and Renewable Energy Wind Energy Technologies Office and the DOE Office of Electricity, in support of the Grid Modernization Initiative. The views expressed in the article do not necessarily represent the views of the DOE or the U.S. Government. The U.S. Government retains and the publisher, by accepting the article for publication, acknowledges that the U.S. Government retains a nonexclusive, paid-up, irrevocable, worldwide license to publish or reproduce the published form of this work, or allow others to do so, for U.S. Government purposes.

\section{REFERENCES}

[1] “Tribune Offers Hydro-Electric System for U.S.," Chicago Sunday Tribune, Vol. LXXXII, Issue 31, pp. 1 and 12, Aug. 5, 1923.

[2] "Coal May Provide Power For West: Reclamation Bureau Pictures Super Transmission System Operated by Steam Plants," The New York Times, p. 7, Dec, 31, 1952.

[3] Western Area Power Administration (WAPA), "East/West AC Intertie Feasibility Study," Golden, CO: WAPA Division of Sys Engr, Aug. 1994.

[4] C. Taylor, "Interconnection of Eastern and Western North American Power Systems in the Early 1980's," Portland, OR: BPA, June 1979.

[5] U.S. Department of Energy, "National Transmission Grid Study," Washington, DC: U.S. Department of Energy, May 2002.

[6] R. Spahr, K. Davis, and D. Mundy, "A feasibility analysis for the TransAmerica Grid Project (TAG) - a national grid proposal," IEEE PES Power Systems Conf \& Exposition, 2004.

[7] J. Fleeman et al.,, "EHVAC and HVDC transmission working together to integrate renewable power," CIGRE/IEEE PES Joint Symp. on Integration of Wide-Scale Renewable Resources into the Power Delivery System, July 29-31, 2009.

[8] J. McCalley, et al., "Transmission design at the national level: benefits, risks, and possible paths forward," Power Systems Engineering Research Center, White Paper, Jan. 2012.

[9] Y. Li and J. McCalley, "Design of a high capacity interregional transmission overlay for the U.S.," IEEE Trans. Power Syst., Vol. 30 , Issue 1, pp. 513-521, 2015.

[10] A. MacDonald, C. Clack, A. Alexander, A. Dynbar, J. Wilczak, and Y. Xie, "Future cost-competitive electricity systems and their impact on US $\mathrm{CO}_{2}$ emissions," Nature Climate Change, Vol. 6, PP. 526-531, Jan. 2016.

[11] J. Smith, et al., "Transmission planning for wind energy in the United States and Europe: status and prospects," Wiley Interdiscip. Rev. Energy Environ., Vol. 2, Issue 1, pp. 1-13, Jan. 2013

[12] J. McCalley, et al., "Wide-area planning of electric infrastructure: assessing investment options for low-carbon futures," IEEE Power and Energy Magazine, Vol. 15, Issue 6, pp. 83-93, 2017.

[13] P. Beiter et al., "The Potential Impact of Offshore Wind Energy on a Future Power System in the U.S. Northeast," Golden, CO: NREL/TP5000-74191, 2020.

[14] North American Reliability Corporoation (NERC) web page for "M-1 Reserve Margin," [Online]. Available www.nerc.com/pa/RAPA/ri/Pages/PlanningReserveMargin.aspx.

[15] A.L. Figueroa-Acevedo, "Opportunities and benefits for increasing transmission capacity between the US eastern and western interconnections," Ph.D. dissertation, 2017.

[16] Black and Veatch, 2014. Capital Costs for Transmission and Substations. Updated Recommendations for WECC Transmission Expansion Planning. B\&V PROJECT NO. 181374. February 2014.

[17] National Academies of Sciences, Engineering, and Medicine. 2017. Valuing Climate Damages: Updating Estimation of the Social Cost of Carbon Dioxide. Washington, DC: The National Academies Press.

[18] U.S. Energy Information Admin. (EIA). "Wind and Solar Data and Projections from the U.S. Energy Information Administration: Past Performance and Ongoing Enhancements." U.S. EIA, March,2016.
[19] U.S. Energy Information Administration, "Annual Energy Outlook 2017," Washington, DC: U.S. Energy Information Administration, 2017.

[20] U.S. Energy Information Administration, "Annual Energy Outlook 2020," Washington, DC: U.S. Energy Information Administration, 2020.

[21] W. Cole et al., "2016 Standard Scenarios: A U.S. Electricity Sector Outlook," Golden, CO: NREL, TP-6A20-66939, 2016.

[22] OMB Circular A-94, Appendix C, Rev. November 2015, "Discount rates for cost-effectiveness, lease purchase and related analyses." [Online]. Available: https://www.whitehouse.gov/omb/circulars_a094/a94_appx-c

[23] OMB Circular A-4, September 17, 2003, "Regulatory analysis." [Online]. http://obamawhitehouse.archives.gov/omb/circulars a004 a-4

[24] W. Short et al., "Regional Energy Deployment System ( ReEDS)," no. November, pp. 1-85, 2011.

[25] Eastern Interconnection Planning Collaborative (EIPC), "Phase 1 Report: Formation of Stakeholder Process, Regional Plan Integration and Macroeconomic Analysis," Dec. 2011.

[26] E3, "CA LSE and WECC load and energy forecasts," Nov. 1, 2007.

[27] E3, "WECC Capital Cost Model," 2014.

[28] NREL, "2016 Annual Technology Baseline," Golden, CO: NREL, 2017.

[29] R. Pletka, J. Khangura, A. Rawlins, E. Waldren, and D. Wilson, "Capital Costs for Transmission and Substations - Updated Recommendations for WECC Transmission Expansion Planning," B\&V Project No. 181374, prepared for Western Electric Coordinating Council, Feb. 2014.

[30] Keane, A. et al., "Capacity Value of Wind Power," IEEE Trans. Power Syst., Vol. 26, Issue 2, pp. 564-572, May 2011.

[31] C.J. Dent et al., "Capacity Value of Solar Power: Report of the IEEE PES Task Force on Capacity Value of Solar Power," International Conference on Probabilistic Methods Applied to Power Systems, Oct. 16-20, 2016.

[32] A. Figueroa-Acevedo, A. Jahanbani Arkadani, H. Nosair, A. Venkatraman, J. Novacheck, and J. McCalley, "Benefits of increasing transmission capacity between the US Eastern and Western Interconnections," under review by IEEE Trans. Power Syst.

[33] C. Barrows, et al., "The IEEE Reliability Test System: A proposed 2019 Update." IEEE Transactions on Power Systems. 30:1, 2020.

[34] C. Barrows, B. McBennett, J. Novacheck, D. Sigler, J. Lau, and A. Bloom, "A Multi-operator Approach to Production Cost Modeling at Scale", IEEE Transactions on Power Systems. 30:6, 2019.

[35] M. Rossol, et al. "An Analysis of Thermal Plant Flexibility Using a National Generator Performance Database," Environ. Sci. Technol. 2019, $53,22,13486-13494$.

[36] E. Ibanez et al. "A Solar Reserve Methodology for Renewable Energy Integration Studies," Golden, CO: NREL, CP-5500-56169, Aug. 2012.

[37] U.S. Federal Energy Regulatory Commission (FERC): 18 CFR Part 35, Docket No. RM10-23-000, Order No. 1000: Transmission Planning and Cost Allocation by Transmission Owning and Operating Public Utilities. FERC, July 21,2011 .

\section{BIOGRAPHIES}

Aaron Bloom (M13) was employed with the US FERC from 2005 to 2012 and with NREL from 2012 to 2018. He is now with NextEra Analytics.

Josh Novacheck (M15) is a researcher with the National Renewable Energy Laboratory

Greg Brinkman (M13) is an engineer with the National Renewable Energy Laboratory.

James McCalley (F03) is Distinguished Professor at Iowa State University. He was with PG\&E as a transmission planning engineer from 1985-' 90 .

A. Figueroa-Acevedo (M08) received the $\mathrm{Ph}$. D. in EE from Iowa State University in 2017 and was employed with MISO from 2017-2020. He is now a Consultant with Black and Veatch.

A. Jahanbani-Ardakani received the Ph. D. in EE from McGill University in 2014 and has been a research associate at Iowa State University since 2015.

H. Nosair received the Ph. D. in EE from McGill University in 2015 and is now an engineer in public policy and interregional planning at NYISO.

A. Venkatraman (M15) received his MS degree in Electrical Engineering in 2016 from Iowa State University, where he is currently a PhD student.

J. Caspary originated the idea of the Interconnections Seam Study. He is a Vice President with Grid Strategies, LLC, formerly the director of research, development, and tariff services at the Southwest Power Pool.

D. Osborn (LM18) is the architect of Design 3, the Macrogrid overlay. He is a retired engineer from the Midcontinent Independent System Operator.

Jessica Lau (M07) is a grid systems researcher and technical project manager at the National Renewable Energy Laboratory. 